\title{
Audiology
}

\section{Idiopathic sensorineural hearing loss in the only hearing ear}

\author{
Ipoacusia neurosensoriale idiopatica nell'unico orecchio udente
}

\author{
S. BERRETTINI ${ }^{1,2}$, A. DE VITO'1, L. BRUSCHINI ${ }^{1}$, S. FORTUNATO1 ${ }^{1}$, F. FORLI ${ }^{1}$ \\ ${ }^{1}$ ENT, Audiology and Phoniatrics Universitary Unit of "Azienda Universitaria Ospedaliera Pisana" Pisa, Italy; ${ }^{2}$ Guest \\ Professor at Division of ENT Diseases, Karolinska Institutet, Stockholm, Sweden
}

\section{SUMMARY}

A retrospective chart review was used for 31 patients with sudden, progressive or fluctuating sensorineural hearing loss (SHL) in the only hearing ear who had been consecutively evaluated at the ENT, Audiology and Phoniatrics Unit of the University of Pisa. The group of patients was evaluated with a complete history review, clinical evaluation, imaging exam (MRI, CT), audiologic tests (tone and speech audiometry, tympanometry, study of stapedial reflexes, ABR and otoacoustic emission) evaluation. In order to exclude genetic causes, patients were screened for CX 26 and CX30 mutations and for mitochondrial DNA mutation A1555G. Patients with sudden or rapidly progressive SHL in the only hearing ear were treated with osmotic diuretics and corticosteroids. In patients who did not respond to intravenous therapy we performed intratympanic injections of corticosteroid. Hearing aids were fitted when indicated and patients who developed severe to profound SHL were scheduled for cochlear implant surgery. The aim of this study is to report and discuss the epidemiology, aetiopathogenesis, therapy and clinical characteristic of patients affected by SHL in the only hearing hear and to discuss the issues related to the cochlear implant procedure in some of these patients, with regard to indications, choice of the ear to implant and results.

KEY WORDS: Sensorineural hearing loss • Only hearing ear • Progressive sensorineural hearing loss • Cochlear implant

\section{RIASSUNTO}

Uno studio retrospettivo è stato condotto su 31 pazienti, giunti all'osservazione della cinica ORL Audiologia e Foniatria dell'Università di Pisa dal 2007 al 2013, affetti da ipoacusia neurosensoriale improvvisa, fluttuante o progressiva nell'unico orecchio udente. L'intero gruppo di pazienti è stato valutato con una adeguata anamnesi, otomicroscopia, esami di imaging (TC RMN), test audiologici (audiometria tonale e vocale, impedenziometria, potenziali evocati uditivi e otoemissioni acustiche). Questo gruppo di pazienti è stato sottoposto anche a una valutazione genetica (ricerca mutazioni CX 26, CX 30 e DNA mitocondriale A1555G) e a test di laboratorio. I pazienti con ipoacusia improvvisa o rapidamente progressiva sono stati trattati con diuretici osmotici e corticosteroidi (endovena o intratimpanici). $I$ pazienti che non hanno recuperato in maniera adeguata dopo il trattamento sono stati avviati a un percorso di protesizzazione. Nei pazienti con insufficiente resa protesica sono stati sottoposti ad impianto cocleare. Lo scopo di questo studio è quello di discutere l'epidemiologia, l'eziopatogenesi e le caratteristiche cliniche di pazienti affetti da ipoacusia neurosensoriale nell'unico orecchio udente e inoltre discutere le indicazioni e la scelta dell'orecchio da impiantare in questa categoria di pazienti.

PAROLE CHIAVE: Ipoacusia neurosensoriale $\bullet$ Unico orecchio udente $\bullet$ Ipoacusia progressiva $\bullet$ Impianto cocleare

Acta Otorhinolaryngol Ital 2016;36:119-126

\section{Introduction}

Patients suffering from severe to profound unilateral sensorineural hearing loss (SHL) in one ear can develop idiopathic SHL in the contralateral ear after a period varying from months to years. This condition may be sudden, progressive or fluctuating. The development of SHL is a dramatic event leading patients with an only hearing ear to be confused, worried, anxious and isolated from the surrounding world, and thus worthy of special consideration. This small subpopulation of patients becomes practically deaf, so that SHL in the only hearing ear is an audiologic emergency. So far, it has not been possible to provide any specific therapy, while steroids, vasodilators and diuretics are frequently prescribed. Cochlear implants are often the last resort to rehabilitate these patients when medical therapy and hearing aids do not result in satisfactory hearing performance.

We believe it is of interest to investigate the clinical characteristics of this specific group of patients because the scientific literature describing this "disease" is relatively limited. To our knowledge, the aetiopathogenesis and incidence of this clinical condition have never been previously reported. There are only a few studies reporting on sudden SHL ${ }^{1-4}$ in the only hearing ear, but none describing the progressive forms of the disease.

In this regard, delayed endolymphatic hydrops (DEH) is 
a clinical entity that may present with features similar to SHL in the only hearing ear. This disease, first reported by Nadol et al. in $1975^{5}$, is characterised by the early onset of profound or total SHL in one ear. After a prolonged period of stagnation, a late phase of the disease appears with different otologic symptoms that can be described as two main types of DEH: ipsilateral and contralateral variants. Ipsilateral DEH appears with episodic vertigo in the deaf ear, while contralateral DEH appears as fluctuating hearing loss and/or episodic vertigo in the previously normal ear. In contralateral DEH, the SHL first affects the low-tone frequencies and is always fluctuating ${ }^{6}$.

In this paper, we report on a retrospective case series of 34 patients (collected over 6 years) with one deafened ear - as a result of various causes - who subsequently developed progressive, fluctuating or sudden SHL in the contralateral ear. The aim is to present and discuss epidemiology, aetiopathogenesis and clinical characteristics of patients affected by SHL in the only hearing hear and to discuss the issues related to the cochlear implant procedure in these patients with regards to indications, choice of the ear to implant and results.

\section{Materials and methods}

A retrospective chart review was used for 34 patients with SHL in the only hearing ear who had been consecutively evaluated at the Ear, Nose and Throat (ENT) Audiology and Phoniatrics Unit of the University of Pisa (tertiary referral centre for audiological disease) between January 2007 and January 2013. The sample was composed of 19 men and 15 women. All data were collected after receiving informed consent by all patients involved and according to the Declaration of Helsinki. All patients were evaluated with a complete history review (with particular attention to family history and other systemic diseases). Patients underwent otomicroscopy, pure tone audiometry, speech audiometry, tympanometry and study of stapedial reflexes. All patients were also evaluated with auditory brainstem responses and otoacoustic emissions. Patients who complained of dizziness underwent vestibular examination with videonystagmography.

Several blood tests were carried out to exclude any known cause of hearing loss (complete blood cell count, general chemistry screen, VES, PCR, mucoproteins, fibrinogen, urine test, total and fractionated protein, bilirubin, vGT, LDH, SGOT, SGPT, CPK, TSH, T3, T4, serological tests for toxoplasmosis, syphilis, borrelia burgdorferi, antibodies ANA ENA, AMA, ASMA, CLIF test, ANCA). In order to exclude genetic causes, patients were screened for connexin 26 and connexin 30 mutations and for the most frequent mitochondrial DNA mutation related to deafness (A1555G). Patients were also evaluated with 1.5-3.0 Tesla contrast-enhanced magnetic resonance imaging (MRI) of the brain, cerebellopontine angle and inner ear. The study protocol of the inner ear includes a thin slice heavily $\mathrm{T} 2 \mathrm{~W}$ 3D sequence (FIESTA) to stress the signal difference between the cerebrospinal fluid (CSF) and other tissues, and thin axial and coronal SE or FSE 2D T1W with and without gadolinium administration. Axial FLAIR imaging was performed, which covered the entire brain. All patients underwent CT scan of petrous bone to exclude advanced otosclerosis, perilymphatic fistulas or other bone pathologies. Patients with a history of hypertension or cardiovascular disease were also evaluated with colour Doppler ultrasound of neck vessels.

Patients with known autoimmune diseases, vascular diseases, diabetes and other metabolic systemic diseases were excluded.

Out of 34 patients three were excluded: one because of the presence of a mutation in the connexin 26 gene (M34T), another for an enlarged bilateral vestibular aqueduct (EVA) and one because of the presence of superficial hemosiderosis of the central nervous system. This patient experienced unilateral profound deafness after a head trauma with a temporal bone fracture and some years later developed fluctuating progressive SHL in the contralateral ear ${ }^{7}$.

In 18 of the 31 patients included, the aetiology of SHL in the first deafened ear was unknown and was defined as idiopathic; in 6 patients SHL was due to ear surgery (1 patient with translabyrinthine surgery for acoustic neuroma; in 5 patients deafness was due to tympanoplasty for cholesteatoma or middle ear chronic otitis with postoperative severe or profound SHL). In another patient SHL was subsequent to a head trauma with a temporal bone fracture. An infectious aetiopathogenesis (bacterial meningitis, acute otitis media, systemic viral infection etc.) was recognised in another 6 cases.

Idiopathic SHL occurring in the second affected ear was classified as follows:

- progressive: $\mathrm{SHL} \geq 15 \mathrm{~dB}$ HL (PTA at $0.5-1-2-4 \mathrm{kHz}$ ) occurring in a 10 -year period ${ }^{8}$;

- sudden: abrupt hearing deterioration of $\geq 30 \mathrm{~dB} \mathrm{HL}$ in at least 3 consecutive frequencies occurring in a period no longer than 3 days ${ }^{9}$;

- progressive-fluctuating: recurrent episodes of SHL of any entity that recover rapidly.

The entire group of patients was evaluated by the same audiological team and submitted to the battery of audiological tests that we routinely use to evaluate patients with progressive, fluctuating or sudden SHL (Table I).

Patients with sudden or rapidly progressive SHL in the only hearing ear were treated with glycerol $10 \% 500 \mathrm{ml} /$ day i.v. for 7 days, methylprednisolone $250 \mathrm{mg} /$ day for 3 days, and then tapered for a 15-day period and a proton pump inhibitor (lansoprazole $30 \mathrm{mg} / \mathrm{die}$ ) was added. In patients who did not respond to intravenous therapy we performed intratympanic injections of dexamethasone (4 $\mathrm{mg} / \mathrm{ml} 3$ injections for 10 days). Hearing aids were fitted 
Table I. Protocol of clinical evaluation for SHL in the only hearing ear.

$\begin{array}{ll}\text { Auditory test } & \text { Tonal and speech audiometry } \\ & \text { Tympanometry study of stapedial reflex } \\ & \text { ABR and otoacustic emission } \\ \text { Auditory skills test }\end{array}$

when indicated and patients who developed severe to profound SHL were scheduled for cochlear implant surgery.

\section{Results}

The mean age of patients when SHL occurred in the first ear was 28.09 years (age range $0-62$ years). The mean pure tone average (PTA between $0.5 \mathrm{kHz}$ and $1 \mathrm{kHz}$, and $2 \mathrm{kHz}$ ) in the first deafened ear was $82.03 \mathrm{~dB}$ (range 70 dB-120dB). SHL occurred in the contralateral ear after a mean period of 25.09 years (age range 2-57 years). The onset of SHL in the contralateral ear was sudden in 12 patients, progressive in 13 cases and progressive with fluctuations in another 6 cases.

With regards to the hearing threshold curve in the second affected ear, 18 patients developed downsloping SHL, 4 patients upsloping SHL and the last 9 patients a flat curve SHL. The mean mean pure tone audiometry (PTA) in the second ear that developed a hearing loss was $42.03 \mathrm{~dB}$ (range 30-120 dB) (Table II).

Eleven of 31 patients complained monolateral tinnitus (only in the first ear interested by SHL), while 20 of 31 complained of bilateral tinnitus. Four of 31 patients complained of occasional and non-recurrent vertigo, not temporally related to the development of SHL.

Of the 18 patients with sudden or rapidly progressive SHL in the second ear, 5 ( \# 1, 7, 18, 25, 26) were treated with the above-mentioned mentioned protocol; the remaining
13 patients referred to our clinic over 6 months after the onset of SHL and with no indications to medical treatment. In these patients, the mean PTA before therapy was $59.6 \mathrm{~dB}$ and $47.6 \mathrm{~dB}$ after therapy with a mean improvement of $12.0 \mathrm{~dB}$.

Hearing aids fitting in the best hearing ear, or bilaterally when indicated, was proposed to 25 of 31 patients. In 17 of 25 patients, hearing performance were good: mean open-set speech-recognition score in silence was $78.8 \%$ (range 60-100\%). While in 8 of 25 patients (\# 3, 8, 11, 27, $28,29,30,31)$ the hearing performance with hearing aids was very poor (mean open-set speech-recognition score in silence $25.6 \%$, range $0-45 \%$ ), and cochlear implant surgery was proposed. Patients 3 and 11 declined the cochlear implant (CI) procedure. The remaining 6 patients were implanted by using a Nucleus Contour Advance CI24RE (Cochlear) (Table III). Of a group of 184 patients (both children and adults), 6 were implanted in the same period (2007-2013). All patients were operated by the same surgical team and the final insertion of the $\mathrm{CI}$ was performed by the same senior surgeon. The array of electrodes was fully inserted in all cases. A post-operative X-ray of the skull was performed to confirm the correct placement of the implant. Five of six patients were implanted in the second deafened ear, while one patient (\# 8) was implanted in the first deafened ear. The mean preoperative openset speech-recognition score in silence was 20\% (range $0-40 \%$ ). The mean post-operative score (Table III), measured 1 year after the switch-on of the implant, was $83 \%$ (range 70-100\%) with a significant improvement in hearing performance.

\section{Discussion}

\section{Epidemiology}

To our knowledge, there are no papers in the literature reporting epidemiologic data of idiopathic SHL in the only hearing ear.

Few reports 121011 on sudden SHL in the only hearing ear have been published. Stahl and Cohen ${ }^{2}$ reported that $20 \%$ of patients with sudden SHL were deaf in the contralateral ear (9 of 45 patients), while Lee et al. ${ }^{1}$ reported a percentage of $11.5 \%$ ( 25 out of 217 patients). Fetterman et al. ${ }^{12}$ found that $1.7 \%$ of patients (14/823 patients) with sudden SHL had bilateral loss. Shaia and Sheehy ${ }^{11}$ reported 1,220 cases of sudden SHL observed at the House Ear Clinic from 1964 to 1972, 4\% of which were bilateral. Half of their cases occurred simultaneously while the others were sequential. Therefore, the occurrence of sudden SHL seems to be a rather common event in patients with only one hearing ear, and more frequent than sudden SHL in the normal population, which is reported to be 5 to 160 per 100,000 ${ }^{13-14}$. Concerning the involvement of the only hearing ear, patients with progressive or fluctuating SHL (19/31 or $61 \%$ in our sample) should be added to patients 
Table II. Patients and clinical characteristics.

\begin{tabular}{|c|c|c|c|c|c|c|c|c|}
\hline & Age & $\begin{array}{l}\text { Age of } \\
\text { first } \\
\text { SHL }\end{array}$ & $\begin{array}{l}\text { Aetiology } \\
\text { first } \\
\text { SHL }\end{array}$ & $\begin{array}{c}\text { Age SHL } \\
\text { contralateral } \\
\text { ear }\end{array}$ & $\begin{array}{l}\text { PTA } \\
\text { first } \\
\text { ear }\end{array}$ & $\begin{array}{l}\text { PTA } \\
\text { second } \\
\text { ear }\end{array}$ & $\begin{array}{c}\text { Development } \\
\text { SHL in the second ear }\end{array}$ & Audiometric curve \\
\hline 1 & 45 & 18 & Idiopathic & 42 & 73 & 80 & Sudden & Downsloping \\
\hline 2 & 50 & 28 & Idiopathic & 50 & 78.3 & 60 & Fluctuating & Downsloping \\
\hline 3 & 76 & 61 & Surgery for neuroma & 63 & 120 & 80 & Progressive & Downsloping \\
\hline 4 & 32 & 5 & Infective & 30 & 120 & 70 & Fluctuating & Downsloping \\
\hline 5 & 62 & 38 & Idiopathic & 52 & 87 & 90 & Progressive & Downsloping \\
\hline 6 & 70 & 60 & Idiopathic & 69 & 70 & 30 & Progressive & Upsloping \\
\hline 7 & 69 & 55 & Infective (OMC) & 57 & 120 & 50 & Sudden & Downsloping \\
\hline 8 & 57 & 41 & Idiopathic & 52 & 120 & 80 & Progressive & Downsloping \\
\hline 9 & 36 & 15 & Idiopathic & 34 & 120 & 32.5 & Fluctuating & Upsloping \\
\hline 10 & 75 & 14 & Surgery for OMC & 65 & 95 & 65 & Progressive & Downsloping \\
\hline 11 & 75 & 14 & Trauma & 65 & 120 & 100 & Progressive & Pantonal \\
\hline 12 & 60 & 5 & Infective & 60 & 70 & 57 & Sudden & Downsloping \\
\hline 13 & 72 & 62 & Surgery for OMC & 72 & 73 & 63 & Sudden & Downsloping \\
\hline 14 & 66 & 9 & Infective & 65 & 120 & 50 & Progressive & Upsloping \\
\hline 15 & 72 & 33 & Surgery for OMC & 70 & 110 & 45 & Progressive & Downsloping \\
\hline 16 & 71 & 47 & Surgery for OMC & 52 & 90 & 86.25 & Progressive & Pantonal \\
\hline 17 & 61 & 6 & Surgery for OMC & 54 & 120 & 47.5 & Fluctuating & Downsloping \\
\hline 18 & 53 & 1 & Infective & 38 & 112.5 & 40 & Sudden & Downsloping \\
\hline 19 & 64 & 62 & Idiopathic & 64 & 82.5 & 70 & Sudden & Downsloping \\
\hline 20 & 45 & 1 & Idiopathic & 38 & 120 & 58.75 & Sudden & Downsloping \\
\hline 21 & 65 & 48 & Idiopathic & 57 & 120 & 77.5 & Sudden & Downsloping \\
\hline 22 & 29 & 2 & Infective & 16 & 120 & 35 & Sudden & Upsloping \\
\hline 23 & 22 & 0 & Idiopathic & 21 & 120 & 46.7 & Progressive & Pantonal \\
\hline 24 & 58 & 4 & Idiopathic & 29 & 116.7 & 50 & Progressive & Pantonal \\
\hline 25 & 68 & 48 & Idiopathic & 63 & 90 & 35 & Fluctuating & Pantonal \\
\hline 26 & 44 & 0 & Idiopathic & 42 & 105 & 33 & Fluctuating & Downsloping \\
\hline 27 & 74 & 14 & Idiopathic & 71 & 120 & 73.3 & Sudden & Downsloping \\
\hline 28 & 65 & 60 & Idiopathic & 65 & 81.6 & 120 & Sudden & Pantonal \\
\hline 29 & 69 & 40 & Idiopathic & 66 & 120 & 78.3 & Progressive & Pantonal \\
\hline 30 & 70 & 60 & Idiopathic & 69 & 113.3 & 76.6 & Sudden & Pantonal \\
\hline 31 & 65 & 20 & Idiopathic & 58 & 98.3 & 101.6 & Progressive & Pantonal \\
\hline 32 & 52 & 20 & M34T & 41 & 115 & 45 & Progressive & Pantonal \\
\hline 33 & 45 & 6 & EVA & 15 & 80 & 40 & Fluctuating & Pantonal \\
\hline 34 & 75 & 50 & Trauma_SS & 70 & 120 & 52.5 & Progressive & Downsloping \\
\hline
\end{tabular}

Table III. Patient who underwent a $\mathrm{Cl}$ procedure.

\begin{tabular}{lccccc} 
Patient n & $\begin{array}{c}\text { Ear implanted: } \\
\mathbf{1}^{\text {st }} \text { ear or } \mathbf{2}^{\text {nd }} \text { ear }\end{array}$ & $\begin{array}{c}\text { Auditory skills test } \\
\text { recognition open-set } \\
\text { bisyllabic word in silence }\end{array}$ & $\begin{array}{c}\text { Use of bimodal } \\
\text { hearing stimulation }\end{array}$ & $\begin{array}{c}\text { Time from onset of } \\
\text { HL in the implanted } \\
\text { ear }\end{array}$ & $\begin{array}{c}\text { Use of hearing aid in the } \\
\text { ear implanted before } \\
\text { surgery }\end{array}$ \\
8 & $1^{\text {st }}$ & $70 \%(100 \%$ IC+HA) & Yes & 16 years & Yes (for 5 years) \\
27 & $2^{\text {nd }}$ & $85 \%$ & No & 3 years & Yes (for 2 years) \\
28 & $2^{\text {nd }}$ & $80 \%$ & Yes & 3 months & No \\
29 & $2^{\text {nd }}$ & $75 \%$ & No & 3 years & Yes (for 1 year) \\
30 & $2^{\text {nd }}$ & $100 \%$ & No & 2 months & No \\
31 & $2^{\text {nd }}$ & $90 \%$ & No & 6 years & Yes (for 4 years) \\
\hline
\end{tabular}


affected by sudden SNHL. This has led us to think that the development of SHL in the two ears is not an independent event, but that it could be related to aetiopathogenetic factors.

We believe that the possibility of developing SHL in the only hearing ear is not a negligible fact and that further epidemiologic studies should be conducted in this particular group of patients to better understand the risks for patients with an only hearing ear to develop SHL in the contralateral ear.

\section{Aetiology}

The aetiological study of hearing loss is greatly important for both comprehensive treatment of disease and prognosis. The aetiology of this condition has been the subject of numerous reports in the literature, but to our knowledge no data are available concerning the aetiology of hearing loss in patients with an only hearing ear. In the past years our group has made a great effort to investigate the aetiology of hearing loss, in particular of progressive SHL and, as previously described ${ }^{8}$, we have defined the following causes: genetic mutations, inner ear malformations, infectious diseases, autoimmune disease, neoplastic, trauma, etc. Patients with hearing loss, especially those with an only hearing ear should be submitted to accurate and comprehensive aetiologic evaluation to investigate a possible correlation between the aetiology and the risk of developing a contralateral SHL.

Despite the comprehensive aetiological study in our patients, the aetiology of SHL in the only hearing ear remains unknown in a high percentage of these patients (31/34 patients, 91\%). Therefore, we defined the disease as idiopathic and can only make some hypotheses on its origins.

A first hypothesis is genetic: unknown genetic mutations might lead to the development of SHL, possibly with a time lapse between the two ears.

A second hypothesis is the presence of microscopic osseous or membranous labyrinth malformations that are not visible at the resolution of our diagnostic tools. The most recent imaging techniques have revealed inner ear malformations in a relevant percentage of patients affected by SHL. The data, reported in the scientific literature, mainly concern the paediatric population with a reported prevalence of inner ear malformations in children with profound SHL between $14-30 \%{ }^{15}$. However, minor malformations or malformations limited to the membranous labyrinth, not detectable with common diagnostic tools, may be responsible for some cases of SHL of unknown origin.

A third hypothesis is the viral one. Some authors have hypothesised two different possibilities in the development of SHL by viral damage. Schuknecht et al. ${ }^{16}$ explained the genesis of $\mathrm{DEH}$, and hypothesised a praecox viral labyrinthopathy leading to early cochleo-vestibular damage in one ear with subsequent delayed hydrops in the contralateral ear due to an alteration of endolymph production and resorption. Other authors ${ }^{17}$ have considered that a praecox viral infection could be responsible for SHL in the first ear and then a delayed reactivation of the same virus could cause SHL in the second ear. They found the genome cytomegalovirus (CMV) within the cochlea of a deaf patient with no evidence of acute infection. The presence of this virus suggested a possible role in inner ear injury through reactivation of the latent virus within the cochlea.

A final possible hypothesis is the autoimmune one. To explain the genesis of DEH, our group ${ }^{18}$ hypothesised that contralateral hydrops could be mediated by an autoimmune process. We found an non-specific immunological pattern that was altered in $50 \%$ of patients with $\mathrm{DEH}$ and was significantly higher than in patients affected by Ménière's disease. A similar hypothesis is that SHL in the contralateral ear may be caused by an autoimmune mechanism involving recirculating memory cells sensitised against cochlear tissues. A comparable mechanism is described in ophthalmology, which is called sympathetic ophthalmia ${ }^{19}$ in which there is an inflammatory reaction in the healthy eye after a traumatic destruction of the other eye. The pathologic mechanism could be explained as follows: during an infection, trauma, or surgery there is exposure of anatomically sequestered proteins of the inner ear. These proteins, recognised as 'foreign', serve as antigens, and result in the induction of lymphocytes. These cells re-circulate as memory cells and reach the intact contralateral cochlea, thus leading to immune response and damage of the organ. In 1994, Gloddek et al. ${ }^{20}$ described an animal model of this "sympathetic cochleolabyrinthitis". They found a high percentage of sensitised lymphocytes on the apical turn of the cochlea that is not in agreement with the clinical findings herein, since the patients examined in this study (18/31) mainly showed a downsloping audiometric curve.

\section{Clinical issues and therapies}

In reviewing the literature, we found a number of studies reporting patients with sudden SHL in the only hearing ear and describing their clinical features, treatment and results (Table IV) ${ }^{1-4}$. The samples ${ }^{1-4}$ (Table IV) were heterogeneous and the therapy protocols were different, so that it was difficult to compare the results and efficacy of the therapies.

In 2006, Stahl and Cohen ${ }^{2}$ reported 9 cases of patients affected by sudden SHL in the only hearing ear, and described the clinical characteristics of patients and features of the hearing threshold curve. The authors treated patients with prednisolone $60-80 \mathrm{mg} /$ day, who achieved a mean improvement of $9 \pm 8.7 \mathrm{~dB}$ in the three main affected frequencies. Stahl and Cohen ${ }^{2}$ concluded that patients affected by a sudden SHL in the only hearing ear might 
Table IV. Studies reporting patients with sudden SHL in the only hearing ear.

\begin{tabular}{|c|c|c|c|c|c|c|c|}
\hline Article & Year & Patients & $\begin{array}{l}\text { Aetiology of } \\
1^{\text {st }} \text { ear HL }\end{array}$ & $\begin{array}{l}\text { Development of } \\
2^{\text {nd }} \text { ear HL }\end{array}$ & $\begin{array}{c}\text { Type of } \\
\text { audiometric curve } \\
\text { in the } 2^{\text {nd }} \text { ear }\end{array}$ & Treatment & $\begin{array}{l}\text { Cochlear } \\
\text { implant }\end{array}$ \\
\hline $\begin{array}{l}\text { Stahl and } \\
\text { Cohen }\end{array}$ & 2006 & 9 & - & Sudden & $\begin{array}{l}4 \text { Downsloping } \\
5 \text { Upsloping }\end{array}$ & $\begin{array}{c}\text { Prednisolone 60-80 } \\
\text { mg/day }\end{array}$ & - \\
\hline Lee et al. & 2010 & 25 & $\begin{array}{c}12 \text { idiopathic } \\
7 \text { Inflammatory } \\
2 \text { Trauma } \\
1 \text { Acoustic } \\
\text { Schwannoma } \\
2 \text { AVL }\end{array}$ & Sudden & - & $\begin{array}{l}\text { Prednisolone } 1-1.15 \\
\text { mg/kg/day tapered } \\
\mathrm{MgSO}_{4}(4 \mathrm{~g} / \mathrm{day}) \\
\text { Dextran (10 ml/kg in } \\
5 \% \text { dextrose) } \\
\text { Carbogen Inhalation } \\
\text { Intratympanic injection } \\
\text { if no recovery }\end{array}$ & 6 \\
\hline Hawkings & 2008 & 1 & Congenital & Sudden & Pantonal & Oral steroids & - \\
\hline Pykko et al. & 1997 & 10 & $\begin{array}{l}6 \text { Ménière } \\
1 \text { Cogan } \\
3 \text { Idiopathic }\end{array}$ & $\begin{array}{l}2 \text { Sudden } \\
1 \text { Fluctuating } \\
7 \text { Progressive }\end{array}$ & - & $\begin{array}{c}\text { Azathioprine ( } 25 \mathrm{mg} \text { tid) } \\
\text { Prednisolone (5-15 mg/ } \\
\text { day) after initial dose of } \\
20-40 \mathrm{mg}\end{array}$ & \\
\hline
\end{tabular}

receive the same treatment with corticosteroids as other patients affected by sudden SHL.

Pykko et al. ${ }^{4}$ reported on 10 cases of patients, 6 of whom were affected by Mènière's disease, one by Cogan's syndrome and 3 by idiopathic SHL; they treated patients with corticosteroids and immunosuppressants, and hypothesised an autoimmune genesis of SHL in the contralateral ear. Patients were treated with azathioprine $(25 \mathrm{mg}$ tid) and prednisolone (5-15 mg/day) after an initial dose of $20-40 \mathrm{mg}$ and reported a mean improvement of $22.4 \mathrm{~dB}$. Lee et al. ${ }^{1}$ disposed of a larger case series of 24 patients and were the only authors reporting on patients who had undergone cochlear implantation. They treated patients with prednisolone $1-1.15 \mathrm{mg} / \mathrm{kg} /$ day tapered, $\mathrm{MgSO} 4$ (4 g/day), Dextran (10 ml/kg in 5\% dextrose), Carbogen inhalation and corticosteroid intratympanic injection if there was no improvement. A recovery rate of $64 \%$ was reported.

We treated our group of patients with the following therapeutic protocol: glycerol $10 \% 500 \mathrm{ml} /$ day i.v. for 7 days, methylprednisolone $250 \mathrm{mg} /$ day for 3 days then tapered for a 15-day therapy and a proton pump inhibitor (lansoprazole $30 \mathrm{mg} / \mathrm{day})^{21}$. Patients who did not respond to intravenous therapy after 7 days were submitted to 3 intratympanic injections of dexamethasone $(4 \mathrm{mg} / \mathrm{ml})$ in 10 days.

We treated only 5 (\# $1,7,18,25,26)$ of 18 patients with sudden or rapidly progressive SHL because the remaining 13 patients had referred to our clinic with a time-lapse that was longer than 6 months from the onset of SHL in the second ear, and there were no indications about medical treatment. Mean PTA improvement in treated patients was $12.0 \mathrm{~dB}$ [range $0-24 \mathrm{~dB}$ ]. These results are similar to those found by other authors ${ }^{2}$.

The treatment of sudden idiopathic SHL is debated in the literature and there is currently no evidence of its efficacy.
Recent clinical guidelines ${ }^{22}$ suggest to use only corticosteroids (oral, iv, or intratympanic) as first line therapy and eventually hyperbaric oxygen therapy. Guidelines discourage clinicians from using pharmacologic agents (antivirals, thrombolytics, vasodilators, vasoactive substances, antioxidants) that may have side effects and no documented efficacy. The guidelines also recommend the use of intratympanic injection of corticosteroids as a salvage therapy. In this specific group of patients, we decided to add glycerol to the therapeutic protocol, owing to the analogies between idiopathic SHL in the only hearing ear and contralateral-type DEH. Diuretics significantly improve the hearing of patients with this type of DEH ${ }^{23}$.

\section{Outcomes of CI procedure in patients with SHL}

in the only hearing ear

$\mathrm{CI}$ is a viable option for patients whose hearing deficit becomes bilaterally severe to profound and who no longer benefit from hearing aids.

Only one paper ${ }^{1}$ reported on patients with idiopathic SHL in the only hearing ear that underwent a CI procedure. Six of 25 patients were submitted to CI; the results in terms of reaching the top of the category of auditory performances (CAP) defined as 'use of telephone with known speaker' were good. All these patients were implanted in the second ear that developed SHL. The time necessary to reach CAP was linked to the time of auditory deprivation in the second ear. The authors concluded that a treatment like CI might be considered as early as 3 months so that the patient can return to daily verbal communication.

In our group, 6 of 31 patients underwent a CI procedure; 5 of 6 were implanted in the second ear that developed SHL, and consequently with a shorter deprivation. The hearing performances were very good in all these patients with a mean of $87.5 \%$ [range $75-100 \%$ ] of post-operatively disyllabic word recognition scores. 
Only one patient was implanted in the first ear that developed SHL. This choice was due to the fact that the hearing threshold was significantly better in the second deafened ear (so as to allow the use of a hearing aid, even if with partial results), and also to the fact that the first ear had a history of slight progressive SHL with long term use of a hearing aid. The auditory performances with CI only were good and satisfactory even in this patient, but lower than in the previously reported 6 patients (70\% recognition of bisyllabic words). However, with bimodal stimulation the patient reached $100 \%$ of the recognition score. Moreover, he reported good satisfaction with the implant and benefits in the quality of life.

In patients with bilateral severe to profound SHL, candidates for a CI procedure, the criteria employed for the choice of the ear to implant has changed over the years. If residual hearing in one ear is suitable for hearing aid fitting, implantation in the worse ear is preferred to allow bimodal stimulation. If none of the ears is good for HA fitting, it is usually recommended to implant the ear with less hearing deprivation. Hearing deprivation is one of the stronger predictors of CI outcome in adults with post-verbal hearing loss.

However, in the literature there is no clear agreement on the choice of the side to implant in patients with monoaural sound deprivation. Several authors ${ }^{24-25}$ have reported that implanting the ear with a longer deprivation did not appear to have a negative impact on CI outcome. Notwithstanding, the UK Cochlear Implant Study Group ${ }^{26}$ argued that CI was less effective in the ear with a longer deprivation even if residual hearing is better.

Recently, Boisvert et al. $2012^{27}$ examined speech recognition results in 30 adults with bilateral SHL using only one hearing aid. Fifteen received the implant in the sounddeprived ear and 15 in the aided ear. The authors concluded that there was no significant difference in speech recognition results for the 2 groups when the patient in the group with $\mathrm{CI}$ in the sound deprived ear were tested with bimodal stimulation.

Among the 6 patients of our sample submitted to CI, 5 were not suitable for HA fitting, and the second deafened ear was implanted with good results. We decided to implant the remaining one patient on the first deafened ear, because the second ear was suitable for HA fitting.

\section{Conclusions}

Herein, we focus our attention on progressive, sudden or fluctuating SHL in the only hearing ear. SHL occurrence is not negligible and it would be important to better understand the risk for patients with an only hearing ear to develop SHL in the contralateral one.

We believe a comprehensive diagnostic protocol is mandatory to investigate all known causes of hearing loss (ear malformations, genetic anomalies, superficial siderosis, etc.) and, if possible, to prevent contralateral involvement. Further studies should be conducted in the aetiology, epidemiology and aetiopathogenesis, because at present only hypotheses (genetic, micro-malformation, autoimmune, viral) can be made regarding the genesis of SHL in the only hearing ear.

HA fitting may not be simple for the progression or fluctuation of hearing loss over time, and therefore CI may be indicated in patients that developed a bilateral severe to profound SHL. According to literature data, the results of our patients submitted to CI are satisfactory. Our data (even if the sample is small) seem to indicate that better results can be expected in patients implanted in the ear with a shorter deprivation. Good results can be also achieved in patients implanted in the first deafened ear by using bimodal stimulation.

\section{References}

1 Lee SS, Ho Cho H, Ho Jang C, et al. Fate of sudden deafness occurring in the only hearing ear: outcomes and timing to consider cochlear implantation. J Korean Med Sci 2010;25:283-6.

2 Stahl N, Cohen D. Idiopathic sudden sensorineural hearing loss in the only hearing ear: patient characteristics and hearing outcome. Arch Otolaryngol Head Neck Surg 2006;132:193-5.

3 Hawkins DB. Hearing rehabilitation in a patient with sudden sensorineural hearing loss in the only hearing ear. Am Acad Audiol 2008;19:267-74.

4 Pyykkö I, Ishizaki H, Peltomaa M. Azathioprine with cortisone in treatment of hearing loss in only hearing ear. Acta Otolaryngol Suppl 1997;529:83-5.

5 Nadol JB Jr, Weiss AD, Parker SW. Vertigo of delayed onset after sudden deafness. Ann Otol Rhinol Laryngol 1975;84:841-6.

6 Giannoni B, Pagnini P, Vannucchi P. Delayed endolymphatic hydrops. [Article in Italian]. Acta Otorhinolaryngol Ital Suppl 1998;59:66-70.

7 Berrettini S, De Vito A, Bruschini L, et al. Cochlear implantation in patients affected by superficial hemosiderosis of the central nervous system. Eur Arch Otorhinolaryngol 2012;269:25-31.

8 Berrettini S, Piragine F. Progressive sensorineural hearing loss: definition, classification, main etiological factors. [Article in Italian]. Acta Otorhinolaryngol Ital Suppl 1998;59:9-12.

9 Zadeh MH, Storper IS, Spitzer JB, et al. Diagnosis and treatment of sudden-onset sensorineural hearing loss: a study of 51 patients. Otolaryngol Head Neck Surg 2003;128:92-8.

10 Kirikae I, Matsuzaki T. Clinical observations of bilateral sudden deafness. Audiol Jpn 1967;10:320-5.

11 Shaia FT, Sheehy JL. Sudden sensori-neural hearing impairment: a report of 1,220 cases. Laryngoscope 1976;86:389-98.

12 Fetterman BL, Luxford WM, Saunders JE, et al. Sudden bilateral sensorineural hearing loss. Laryngoscope 1996;106:1347-50. 
13 Byl FM Jr. Sudden hearing loss: eight years' experience and suggested prognostic table. Laryngoscope 1984;94:647-61.

14 Klemm E, Deutscher A, Mosges R. A present investigation of the epidemiology in idiopathic sudden sensorineural hearing loss [in German]. Laryngorhinootologie 2009;88:524-7.

15 Agarwal SK, Singh S, Ghuman SS, et al. Radiological assessment of the Indian children with congenital sensorineural hearing loss. Int J Otolaryngol 2014;2014:808759.

16 Schuknecht HF, Gulya AJ. Endolymphatic hydrops. An overview and classification. Ann Otol Rhinol Laryngol Suppl 1983;106:1-20.

17 Di Nardo W, Cattani P, Lopizzo T, et al. Multiple viral genome search in endolabyrinthic fluids of profoundly deaf patients: possible cytomegalovirus intracochlear reactivation. Audiol Neurootol 2009;14:290-5.

18 Casani A, Fattori B, Berrettini S, et al. Delayed endolymphatic hydrops: an analysis of 12 cases]. [Article in Italian] Acta Otorhinolaryngol Ital 1993;13:297-303.

19 Dreyer WB, Zegarra H, Zakov ZN, et al. Sympathetic ophthalmia. Am J Ophthalmol 1981;92:816-9.

20 Gloddek B, Rogowski M, Arnold W. Adoptive transfer of an autoimmunological labyrinthitis in the guinea pig; animal model for a sympathetic cochleolabyrinthitis Clin Exp Immunol 1994;97:133-7.
21 Berrettini S, Ravecca F, Forli F, et al. Diagnostic and therapeutic approach to progressive sensorineural hearing loss. [Article in Italian]. Acta Otorhinolaryngol Ital Suppl 1998;59:87-94.

22 Stachler RJ, Chandrasekhar SS, Archer SM, et al. Clinical practice guideline: sudden hearing loss. Otolaryngol Head Neck Surg 2012;146:S1-35.

${ }^{23}$ Fujino K, Naito Y, Endo T, et al. Clinical characteristics of delayed endolymphatic hydrops: long-term results of hearing and efficacy of hyperbaric oxygenation therapy. Acta Otolaryngol Suppl 2007;557:22-5.

24 Francis HW, Yeagle JD, Brightwell T, et al. Central effects of residual hearing: implications for choice of ear for cochlear implantation. Laryngoscope 2004;114:1747-52.

25 Chen JM, Shipp D, Al-Abidi A, et al. Does choosing the "worse" ear for cochlear implantation affect outcome? Otol Neurotol 2001;22:335-9.

26 UK Cochlear Implant Study Group. Criteria of candidacy for unilateral cochlear implantation in postlingually deafened adults I: theory and measures of effectiveness. Ear Hear 2004;25:310-35.

27 Boisvert I, Lyxell B, Mäki-Torkko E, et al. Choice of ear for cochlear implantation in adults with monaural sounddeprivation and unilateral hearing aid. Otol Neurotol 2012;33:572-9.

Received: February 1, 2015 - Accepted: September 3, 2015

Address for correspondence: Andrea De Vito, ENT, Audiology and Phoniatrics Universitary Unit of "Azienda Universitaria Ospedaliera Pisana" Ospedale Cisanello, via Paradisa 2, 56124 Pisa, Italy. Fax +39050 997521. E-mail: advvito@gmail.com 